座位行動・身体活動時間の置き換えと日本人オフィスワーカーのメンタルヘルスの関係： isotemporal substitution モデルを用いた検討

小野寺 由美子 ${ }^{1,2}$, 北濃 成樹 ${ }^{1}$, 朽木 勤 $^{3}$, 甲斐 裕子 $^{1}$, 永松 俊哉 ${ }^{1}$, 町田 修一 ${ }^{2}$

\title{
Isotemporal substitution of sedentary time with physical activity and its associations with mental health of Japanese office workers
}

\author{
Yumiko Onodera ${ }^{1,2}$, Naruki Kitano ${ }^{1}$, Tsutomu Kuchiki ${ }^{3}$, Yuko Kai ${ }^{1}$, \\ Toshiya Nagamatsu ${ }^{1}$ and Shuichi Machida ${ }^{2}$ \\ 1 公益財団法人明治安田厚生事業団体力医学研究所， ₹192-0001 東京都八王子市戸吹町 150 (Physical Fitness Research \\ Institute, Meiji Yasuda Life Foundation of Health and Welfare, 150 Tobuki, Hachioji, Tokyo 192-0001, Japan) \\ 2 順天堂大学大学院スポーツ健康科学研究科, =270-1695 千葉県印西市平賀学園台1-1 (Graduate School of Health and \\ Sports Science, Juntendo University, 1-1 Hiraka-Gakuendai, Inzai, Chiba 270-1695, Japan) \\ ${ }^{3}$ 兵庫大学健康科学部, ₹ 675-0195 兵庫県加古川市平岡町新在家 2301 (Department of Health Science, Hyogo University, \\ 2301 Shinzaike, Hiraoka-Chou, Kakogawa, Hyogo 675-0195, Japan)
}

Received: November 29, 2018 / Accepted: May 13, 2019

\begin{abstract}
In this study, we performed isotemporal substitution analysis to examine potential associations of sedentary time and physical activity with mental health of Japanese office workers. This study employed a cross-sectional study design. We analyzed data on 108 Japanese office workers (mean age $46.4 \pm 9.8$ years; $64.8 \%$ women) in the study. Sedentary behavior (SB; $\leq 1.5$ metabolic equivalents [METs]), light-intensity physical activity (LPA; 1.6-2.9 METs), and moderate-to-vigorous physical activity (MVPA; $\geq 3$ METs) were measured with a triaxial accelerometer. Two kinds of self-administered questionnaires, the mental stress (K6) and work engagement (Utrecht Work Engagement Scale), were used to assess negative/positive mental health. A cut-off score of 5 or higher on the K6 was used to define persons with mental stress. Logistic and multiple regression analyses using an isotemporal substitution model was applied to demonstrate the association between replacing $30 \mathrm{~min} / \mathrm{d}$ of SB with an equal amount of time spent on LPA or MVPA and mental stress and work engagement; the studied covariates were age, sex, body mass index, economic status, education, and overtime hours. The results showed that replacing SB with MVPA for $30 \mathrm{~min} / \mathrm{d}$ was significantly decreased odds ratio (OR) of mental stress $(\mathrm{OR}=0.38,95 \%$ confidence interval $0.15-0.92)$, whereas the replacement was not associated with work engagement $(\mathrm{B}=0.16, \mathrm{P}=0.38)$. In contrast, substitution of SB with LPA was not associated with mental stress and work engagement. These results indicate that substituting sedentary time with MVPA could be associated with mental stress of Japanese office workers.
\end{abstract}

Jpn J Phys Fitness Sports Med, 68(4): 261-268 (2019)

Keywords : mental health, sedentary behavior, isotemporal substitution model, office worker, accelerometer

\section{緒言}

世界保健機関は，職場でのヘルスプロモーションを 21 世紀の優先課題と位置づけており，勤労者におけるスト レスの低減や士気向上の取組が期待されている1)。わが 国では勤労者のメンタルヘルスが社会問題となってお り，その対策の一環として2015年12月に従業員に対す るストレスチェック制度 ${ }^{2)}$ が義務化されるなど，働く世 代のメンタルヘルスへの関心が高まっている。 その一方
で，仕事や職業生活に関する強い不安，悩み，ストレス を感じている勤労者が半数以上を占め，2013年以降増加 傾向にあり ${ }^{3)}$, 業務による精神障害の労働災害認定件数 が増加 ${ }^{4)}$ してることがわかっている。そそのため，勤労 者のメンタルヘルス対策は契緊の課題であり，日々活き 活きと過ごし，活力を持って仕事に従事するための戦略 や支援策の開発が求められている.

これまで, システマティックレビューやメタアナリシ スにより，身体活動（physical activity；PA）が将来の抑 
うつ度の悪化を予防することや ${ }^{5)}$ ，職場でのPA促進が メンタルヘルスの改善に効果的6) であることが示されて きた。一方, 一般成人に扔いて長時間の座位行動 (sedentary behavior; SB) がうつ病の発症と関連することがメ タアナリシス ${ }^{7)}$ にってて明らかになっている。最近の公 衆衛生のガイドラインでも, SBを減らし, 中高強度身体 活動 (moderate-to-vigorous-intensity physical activity; MVPA）を増加させることが提唱されており ${ }^{8-10)}$ ，職場 に扔いても勤労者のメンタルヘルス対策の一環として対 策を講じる必要がある。

しかし，PAやSB とメンタルヘルスの関連性を報告し た多くの先行研究の問題点として, 行動の相互依存性を 十分に考慮できていない点が挙げられる。1日は24時間 と有限であり, ある行動（例：運動）を行うには, 別の ある行動時間（例：座位行動）を減らす必要がある。し かし, 先行研究では, PAの好影響 (SBの悪影響) はど のような行動から置き換えられたかによって異なること が想定されるにも関わらず, こうした行動の相互依存性 を考慮できていない. 近年,「isotemporal substitution(IS) モデル」という統計手法を用いた行動の置き換え効果を 検討した研究が増えており, 体重や腹囲等の身体組成関 連, 冠危険因子, 体力, 死亡リスク等に対して, SBから $\mathrm{PA}$ の置き換え効果が示されてきた ${ }^{11-13)}$. しかし， SB から PAへの置き換えとメンタルヘルスとの関連性を検 討した研究 ${ }^{14-19)}$ は乏しい. 特に, 日本人の勤労者を対象 とした研究はなく, 勤労者がSBからどのような PAに置 き換えると, 心理的により健康な状態につながるのかは 明らかではない. 集団によって生活習慣は異なり, オフィ スワーカーか否かは 1 日のSBやPAを規定する大きな要 因といえる。よって，それぞれの集団ごとに研究を実施 し，知見を蓄積していくことが望まれる.

そこで本研究は, 勤労者の心理的ストレスの軽減や活 力に満ちた勤労を支援するための戦略の開発に資する知 見提供を目指し，デスクワークに従事する日本人オフィ スワーカーを対象に客観的評価による SBから PAへの置 き換えとメンタルヘルスの関連性を検討することを目的 とした.

\section{方 法}

対象者 本研究は，2016年11-12月に実施した職場体操 介入研究 ${ }^{20)}$ のベースライン時調査のデータを使用した。 対象は, 東京都内の生命保険会社および関連組織の 2 事 業場に勤務するオフィスワーカー363名のうち, 各事業 場の担当者が加速度計を用いた調查対象 136 名をアトラ ンダムに選定し，これを本研究の対象者とした。そそのう ち, 加速度計と自記式質問紙調查に欠損がある28名（加 速度計デー夕の欠損 14 名, 質問紙調査デー夕の欠損 14 名）を除外し，108名を最終分析対象者とした。対象者
はお抄むね 8 時 30 分頃に出勤し, 17 時 30 分頃に退勤し ており，勤務形態を各事業場の担当者に問い合わせたと ころデスクワークを中心に行う事務従事者であった，な お, 最終分析対象者に占める管理的職業従事者の割合は 17\%（18名）であった。

本研究は, 公益財団法人明治安田厚生事業団倫理審査 委員会の承認を得て実施し (承認番号28004), 対象者に は, 説明書を一読させたうえで参加の同意を得た。

\section{調查項目}

\section{1 ) 座位行動と身体活動}

対象者の SB と PAは, epoch lengthを60秒に設定し た 3 軸加速度計 (Active style Pro HJA-750C, オムロン ヘルスケア株式会社）で評価した，先行研究より，本 機器は, ダイナミックレンジが大きいため感度が良く, 歩行（走行）活動とその他の生活活動それぞれの活動 強度 (metabolic equivalents; METs) が推定されるた $\infty^{21,22)} \mathrm{SB}$ や低強度身体活動（light-intensity physical activity：LPA）の測定に適しているといえる，対象者に は, 加速度計を就寝時と水中活動時（入浴や水泳）を除 き, 起床から就床まで装着するよう指示し, 連続して最 低 26 日間から最大 46 日間装着させた。先行研究に準じ て, 機器の非装着時間は検出閾值以下の活動強度でゼ ロカウントとみなされた活動が20分間以上継続した時 間の合計とし，1日10時間以上装着した日が4 日以上 あるもののみを分析に使用した ${ }^{23)}$ 。装着時間およびSB, PAの解析には, Microsoft Excel VBAで独自に開発し たマクロを用いた，MVPAについては中断時間は考慮 せず，3METs以上のすべての活動の合計時間とした。 な挹，1.5 METs以下の強度を $\mathrm{SB}, 1.6 \sim 2.9 \mathrm{METs}$ LPA，3 METs以上をMVPA と定義し ${ }^{24,25)}$, SB, LPA, MVPA 抢よび, 加速度計の装着時間について 1 日の平均 值を求めた。

\section{2 ）質問紙調査}

\section{（1）基本情報}

自記式質問紙を用いて対象者の年齢, 性, body mass index (BMI), 暮らし向き, 教育年数, 1 週間の残業 時間を調查した。質問紙は, 加速度計と同時に配付し, BMIについては直近の身長と体重を各自が回答した值 から算出した，暮らし向きについては，リッカート尺度 4 件法（大変ゆとりがある, ややゆとりがある, やや苦し い, 大変苦しい) で確認した. 教育年数については, 小学 校以降に受けた学校教育の年数 (例: 高校卒 12 年, 大学 卒16年など）を確認した，残業時間については，基本的 な始業と終業時間を調査し, 加速度計装着日から 1 週間, 1 日ごとの出退勤時間を回答させ，1週間の勤務日の残 業時間を求めた。 
（2）ネガティブメンタルヘルス

ネガティブメンタルヘルスの指標として心理的ストレ ス評価は，うつ病を含む気分・不安障害のスクリーニン グとして妥当性（感度76１00\%，特異度69～80\%）が報 告されているK6質問票日本語版 ${ }^{26)}$ を用いた。本尺度は 6 項目で構成され, リッカート尺度 5 件法で回答するも のである. その合計得点（ 0 〜 24点の範囲）をK6得点と して分析に用いた。 K6 得点が高いほど抑うつ度や不安 感情が高い心理状態であり, 先行研究 ${ }^{27)} に$ 基づき K6 得 点が 5 点以上を心理的ストレスありと定義した。

\section{（3）ポジティブメンタルヘルス}

ポジティブメンタルヘルスの指標としてワークエンゲ イジメント (WE) の評価は, 日本語版ユトレヒトワー クエンゲイジメント尺度短縮版 (UWES-J 短縮版) ${ }^{28)}$ 用いた。WEは仕事に関連するポジティブで充実した心 理状態であり，活力，熱意，没頭によって位置づけられ る ${ }^{29)}$. UWES-J 短縮版 ${ }^{27)}$ は 9 項目で構成され, リッカー 卜尺度 7 件法で回答するものである。合計得点（ 0 〜 54 点の範囲）を項目数で除し，1 項目あたりの平均得点を WE得点として評価 ${ }^{30)} し た 。 W E$ 得点が高いほど仕事に 対してポジティブで充実した心理状態であることを意味 する。

統計解析 SB, PAおよびその置き換えとメンタルヘル スの関連性を検討するにあたって, single factorモデル, partition モデル, IS モデルの 3 つのモデルによる多変量 回帰分析を実施した ${ }^{11,12)}$. 心理的ストレスに関する分析 の際は, 従属変数に心理的ストレスの有無を投入したロ ジスティック回帰分析を実施し, WEに関する分析の際 は, 従属変数にWE得点（連続変数）を投入した重回帰 分析を行った。 なお，両分析において，独立変数には， 結果の解釈を促すために 30 分 1 単位とした各行動変数 を投入した。共変量は各モデルに共通して, 先行研究と 健康科学や産業衛生学の知見に基づき, 座位・身体活動 とメンタルヘルスとの関連に影響を与えると考えられる 年齢 (連続変数 $)^{14,16,17,19)}$, 性 (男/女の名義変数 $)^{14,16-19)}$, BMI (連続変数) ${ }^{16,19,31)}$, 暮らし向き (1. 大変ゆとりがあ る/2. ややゆとりがある/3. やや苦しい/4.大変苦し いの順序変数 $)^{15,16)}$, 教育年数 (連続変数) ${ }^{14-19)}$, 残業時 間 $(\text { 連続変数 })^{32}$ を用いた。 また, 投入した変数間の多重 共線性を確認するため, variance inflation factor (VIF) を算出した。VIFが 5 を超える場合には中程度以上の多 重共線性が発生していると疑われるが33), 本研究で当 該閾值を超えるものはなかった。すべての統計解析には IBM SPSS Statistics ver.24 for Windowsを用い, 有意 水準はいずれも5\%とした. single factor モデル, partitionモデル, IS デルの説明を以下に示した.

\section{1 ) Single factor モデル}

Single factor モデルでは, SB, LPA, MVPAのいずれ か 1 つの行動時間, 加速度計の装着時間, 共変量をモデ ルに投入し，各行動の総合的な関連性を検討した。

\section{2) Partition モデル}

Partition モデルでは, SB, LPA, MVPAのすべての行 動時間と共変量をモデルに投入し, 各行動変数の独立し た関連性を検討した。

\section{3) IS モデル}

IS モデルでは, SB, LPA, MVPAの各行動時間のうち, どれか 1 つを除いて回帰モデルに投入し，さらに，加速 度計の装着時間と共変量をモデルに投入した ${ }^{11,12)}$ 。例え ば，SBからLPAへの置き換えとメンタルヘルスとの関 連性を検証する際には，LPA，MVPA，加速度計の装 着時間，共変量をモデルに投入した。これにより，1日 30分のSBを30分のLPAに置き換えた場合のメンタルヘ ルスとの関連性を検討した。

\section{結 果}

Table1に, 本研究の対象者108名の特性を示した，対 象者の平均年齢は $46.4 \pm 9.8$ 歳で, 70 名 $(64.8 \%)$ が女性で あった．対象者の加速度計の平均装着日数は $22.0 \pm 7.5$ 日 で，1日の装着時間に占めるSB, LPA, MVPAの割合は それぞれ，65.0\%, 27.5\%, 7.5\%であった. K6 得点の平均 值は3.7 4 .1点, 心理的ストレスありの者は34名 (31.2\%) であった，WE得点の平均值は $2.7 \pm 1.1$ 点であった。

ネガティブメンタルヘルス（心理的ストレス）の指標 であるK6得点と各行動時間との関連をTable 2 に示し た、ロジスティック回帰分析の結果, Partition モデル では，各行動との間に有意な関連はみられなかったが, Single factorモデルにおいてMVPAのみが心理的スト レスを有する割合が少ないことと関連した（odds ratio $[\mathrm{OR}]=0.36,95 \%$ confidence interval [CI] 0.15-0.88). また，ISモデルでは，1日30分のSBを等時間のMVPA に置き換えることで心理的ストレスを有するオッズ比が 0.38 と低值だった（OR=0.38, 95\%CI 0.15-0.92）.

ポジティブメンタルヘルス (WE) の指標である WE 得点と各行動時間との関連をTable 3 に示した。分析の 結果, Single factor モデルおよびPartition モデルでは, $\mathrm{SB} P \mathrm{PA}$ と WE得点の間に有意な関連はみられなかっ た。また，ISモデルでも同様に，いずれの行動の置き換 えもWE得点と有意な関連はみられなかった。

\section{考察}

本研究では，デスクワークに従事する日本人オフィ スワーカーを対象に，3 軸加速度計を用いて SB, LPA, 
Table 1. Characteristics of participants in this study

\begin{tabular}{|c|c|}
\hline & Mean \pm SD or number $(\%)$ \\
\hline Age, years & $46.4 \pm 9.8$ \\
\hline \multicolumn{2}{|l|}{ Gender } \\
\hline Male, $n(\%)$ & $38(35.2 \%)$ \\
\hline Female, n (\%) & $70(64.8 \%)$ \\
\hline Body mass index, $\mathrm{kg} / \mathrm{m}^{2}$ & $22.5 \pm 2.7$ \\
\hline \multicolumn{2}{|l|}{ Economic status, n (\%) } \\
\hline Very good & $9(8.3 \%)$ \\
\hline Good & $50(46.3 \%)$ \\
\hline Poor & $40(37.0 \%)$ \\
\hline Very Poor & $9(8.3 \%)$ \\
\hline Education, years & $15.1 \pm 1.7$ \\
\hline Overtime work, hours/wk & $6.1 \pm 6.3$ \\
\hline \multicolumn{2}{|l|}{ Accelerometer data } \\
\hline Valid day, days & $22.0 \pm 7.5$ \\
\hline Wear time, $\mathrm{min} /$ day & $883.1 \pm 88.1$ \\
\hline SB time, $\min /$ day & $573.8 \pm 78.7$ \\
\hline LPA time, $\min /$ day & $243.2 \pm 79.8$ \\
\hline MVPA time, $\min /$ day & $66.2 \pm 18.7$ \\
\hline \multicolumn{2}{|l|}{ K6 } \\
\hline Score, points & $3.7 \pm 4.1$ \\
\hline$\geq 5, \mathrm{n}(\%)$ & $34(31.2 \%)$ \\
\hline Work engagement score, points & $2.7 \pm 1.1$ \\
\hline
\end{tabular}

MVPAを客観的に評価し, SBから PAへの置き換えとメ ンタルヘルスとの関連性を検討した。その結果, 30分の $\mathrm{SB}$ を等時間のMVPAに置き換えると, 心理的ストレス を有する可能性が有意に低值を示した。 また, こうした 恩恵は, SBをLPAへ置き換えた際には認められなかった。

これまでに，ISモデルを用いて行動の置き換えとメ ンタルヘルスとの関連性を検討した研究は少なく, 本研 究と同様に勤労者を対象とした研究は, 筆者が知る限り Mekary ら ${ }^{15)}$ の報告のみである。 Mekary ら ${ }^{15)}$ は，46-71 歳の米国女性看護師 32,900 人を対象に 10 年間追跡した コホート研究において, 質問紙によって調査した60分 のテレビ視聴を等時間の活発な歩行に置き換えるとうつ 病の発症リスクが有意に低值を示し, 通常速度の歩行へ の置き換えではこうした関連性がみられなかったことを 報告した。 また， 3 軸加速度計を用いた研究に, Rethorst ${ }^{16)}$ の研究があげられる. Rethorst ${ }^{16)}$ は, 18-74歳 の米国在住の男女 11,116 人を対象とした横断研究におい て，60分のSBを等時間の高強度PAに置き換えた場合 のみ，抑うつが有意に低值を示したことを報告している。 いずれの研究も, SBを強度の低いPAではなく, 比較的
強度の高いPAに置き換えることでのみ，うつ病や抑う つ度に関連することを示唆しており，本研究結果を支持 するものである. 本研究は 100 名程度の横断研究であり, 上記 2 つ先行研究に比べてサンプルサイズが小さい. しかし, 本研究は加速度計によりオフィスワーカーの行 動を客観的に評価し, 行動の置き換えとメンタルヘルス との関連性を検討した本邦初の研究である。そして, 先 行研究と同様の結果を確認し, こうした知見が立ち・歩 き仕事の多い看護師だけなくデスクワークに従事するオ フィスワーカーにおいても適応できる可能性を一部示し た点で，一定の意義を有していると考える.

本研究では, メンタルヘルスをネガティブな側面（心 理的ストレス）からだけではなく, ポジティブな側面 (WE) からも評価した。WEが高いと心身の健康度が高 く, 高い生産性を示すことが検証されている ${ }^{34)}$. 北アイ ルランドの勤労者を対象とした疫学研究では, 勤務中の $\mathrm{SB}$ が短い者はWEが高いこと ${ }^{35)}$ を報告しており，SBを 減らしてPAを増やすことがWE向上につながると示唆 されている，筆者の知る限り，行動の置き換えとWEの 関連性を検討した研究は見当たらず，本研究は当該仮説 

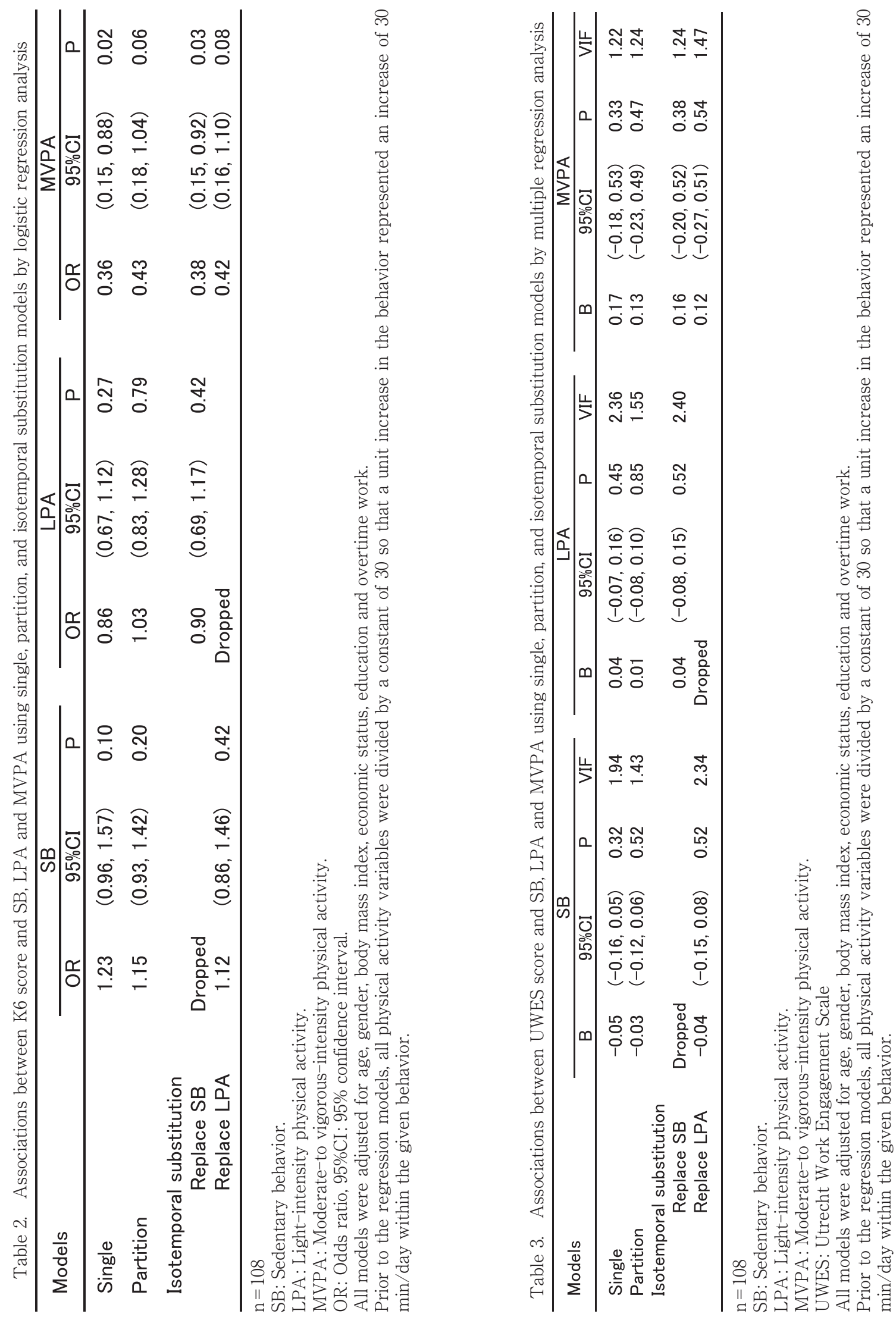
の検証に挑んだ最初の研究であった。しかし，本研究結 果ではSBからLPA P MVPAへの置き換えとWE と有意 な関連は認められなかった。先行研究 ${ }^{36)}$ では, 仕事に関 する感情であるWEは勤務時間外の活動からの影響を受 けにくい可能性があることを指摘している，今回，行動 の置き換えとWEの関連がみられなかったひとつの要因 として, 本研究では余暇時間の SB P PA も含めて測定 · 分析したことが考えられる，今後は，SBやPAのドメイ ンを考慮した研究による知見を積み重ねていくことが望 まれる。

SBをMVPAに置き換えることと心理的ストレスが関 連することのメカニズムは不明であるが, 先行研究では,

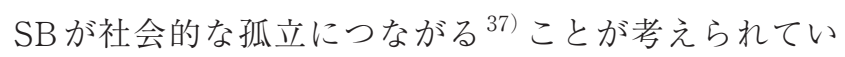
る. 一方, 運動が気晴らしや脳内神経伝達物質 (セロト ニン,ドーパミン,ノルアドレナリンなど）に関与し気分 高揚に関わることなど38) が仮説として提示されており, マイナス要因 $(\mathrm{SB})$ をプラス要因 $(\mathrm{PA})$ に変えることで, ポジティブな関連性がより強まるのかもしれない，今後 は，SBをPAに置き換えることと心理的ストレスが関 連するメカニズムを解明する研究が必要である.

本研究の限界として，第一にサンプルサイズが小さい ことがあげられる，本研究では解析にあたり，各行動変 数に加え結果に影響を与えると考えられる必要最低限の 変数をモデルに投入したが，その数に対してサンプルサ イズが小さいため, 過剩適合が起きている可能性も否定 できない，今後はサンプルサイズを増やして検討する必 要があると考える。第二に, 残差交絡の存在の可能性で ある. 先行研究では, 婚姻状況 ${ }^{14,15,18,19)}$, 雇用形態や職 位 ${ }^{39)}$ などの交絡要因を考慮しているが, 本研究ではサ ンプルサイズが小さく，それらを調整することができな かった，第三に，本研究は横断研究であるため因果関係 に言及することはできず, この限界に対処するためには, 本研究を踏まえた介入研究や縦断研究が必要である. 最 後に, 本研究は東京都内の生命保険会社㧍よび関連組織 に勤務する一部のオフィスワーカーを対象としており， list一wise 削除によって最終分析対象者を決定したため, 選択バイアスを含んでいる可能性がある。また，比較的 メンタルヘルスが良好な集団であったことからも，本研 究結果の一般化には慎重を期す必要がある。

しかしながら, 本研究から得られた知見は, オフィス ワーカーの行動変容を促すメッセージとなるだけでな く, 従業員の健康管理を経営的視点から戦略的に実践す る「健康経営」にも有意義であると考元る。本研究結果 は，雇用者や経営陣がオフィスワーカーの心理的ストレ スを軽減させるための戦略を練る一助となることが期待 される。 さらに,「健康経営」に興味を示さない企業に とっては, 従業員の健康管理を担う者が, 雇用者や経営 陣に働きかけるッールとして貢献できる可能性も考えら
れる. 今後は, 勤務日と休日, 勤務時間内と勤務時間外, 年代や性別ごとの検討や，他の職種やメンタルヘルスが 不良な勤労者のみを対象とした研究に発展させることで 職場でのヘルスプロモーションに活用できる基礎資料が 得られるであろう. IS モデルによる行動の置き換えは, 介入することなく, 心理面, 身体面, 労働生産性などさ まざまな指標と健康行動との関連を検討できることが利 点であり, 職場でのヘルスプロモーションだけでなく, さらに幅広く公衆衛生施策の立案などにも活用できると 考える。

\section{結 語}

本研究では, デスクワークに従事する日本人オフィス ワーカーを対象に，3軸加速度計を用いて客観的に評価 した座位行動および身体活動時間の置き換えとメンタル ヘルスの関連性を検討した。 その結果, 座位行動を等時 間の中高強度の身体活動に置き換えることにより，心理 的ストレスと関連する可能性が示された。

\section{謝 辞}

本研究は, 職場の健康づくり事業の一環として実施した 介入研究のデー夕を活用させていただきました。ご協力い ただいた生命保険会社㧍よび関連会社の職員の皆さまに感 謝いたします。

利益相反自己申告 : 著者全員が利益相反はない.

\section{引用文献}

1) World Health Organization. Workplace health promotion. https://www.who.int/occupational_health/topics/ workplace/en/ (accessed: 2018. 8. 13).

2) 厚生労働省労働基準局. 労働安全衛生法の改正につい て, 2015.

3) 厚生労働省政策統括官. 平成 28 年労働安全衛生調查 (実 態調查), 2017.

4）厚生労働省労働基準局. 平成 28 年度「過労死等の労災 補償状況」, 2017.

5) Mammen G, Faulkner G. Physical activity and the prevention of depression: a systematic review of prospective studies. Am J Prev Med 45: 649-657, 2013. doi: 10.1016/j.amepre.2013.08.001.

6) Joyce S, Modini M, Christensen H, Mykletun A, Bryant R, Mitchell PB, Harvey SB. Workplace interventions for common mental disorders: a systematic metareview. Psychol Med 46: 683-697, 2016. doi: 10.1017/ S0033291715002408.

7) Zhai L, Zhang Y, Zhang D. Sedentary behaviour and the risk of depression: a meta-analysis. $\mathrm{Br}$ J Sports Med 49: 705-709, 2015. doi: 10.1136/bjsports-2014-093613.

8) Owen N, Healy GN, Matthews CE, Dunstan D. Too much sitting: the population-health science of seden- 
tary behavior. Exerc Sport Sci Rev 38: 105-113, 2010. doi: 10.1097/JES.0b013e3181e373a2.

9) Haskell WL, Lee IM, Pate RR, Powell KE, Blair SN, Franklin BA, Macera CA, Heath GW, Thompson PD, Bauman A. Physical activity and public health: updated recommendation for adults from the American College of Sports Medicine and the American Health Association. Med Sci Sports Exerc 39: 1423-1434, 2007. doi: 10.1249/mss.0b013e3180616b27.

10) 2018 Physical Activity Guidelines Advisory Committee. Physical activity guidelines for Americans 2nd edition. http://health.gov/paguidelines/second-edition/ pdf/Physical_activity_Guidelines_2nd_edition.pdf (accessed: 2019. 1. 13).

11) Mekary RA, Willett WC, Hu FB, Ding EL. Isotemporal substitution paradigm for physical activity epidemiology and weight change. Am J Epidemiol 170: 519-527, 2009. doi: 10.1093/aje/kwp163.

12）笹井浩行, 中田由夫：運動疫学研究に活用可能な新しい 解析アプローチ〜Isotemporal Substitution Model , 運 動疫学研究, 17: 104-112, 2015.

13) Grgic J, Dumuid D, Bengoechea EG, Shrestha N, Bauman A, Olds T, Pedisic Z. Health outcomes associated with reallocations of time between sleep, sedentary behaviour, and physical activity: a systematic scoping review of isotemporal substitution studies. Int J Behav Nutr Phys Act 15: 69, 2018. doi: 10.1186/s12966-0180691-3.

14) Buman MP, Hekler EB, Haskell WL, Pruitt L, Conway TL, Cain KL, Sallis JF, Saelens BE, Frank LD, King AC. Objective light-intensity physical activity associations with rated health in older adults. Am J Epidemiol 172: 1155-1165, 2010. doi: 10.1093/aje/kwq249.

15) Mekary RA, Lucas M, Pan A, Okereke OI, Willett WC, Hu FB, Ding EL. Isotemporal substitution analysis for physical activity, television watching, and risk of depression. Am J Epidemiol 178: 474-483, 2013. doi: 10.1093/aje/kws590.

16) Rethorst CD, Moncrieft AE, Gellman MD, Arredondo EM, Buelna C, Castañeda SF, Daviglus ML, Khan UI, Perreira KM, Sotres-Alvarez D, Stoutenberg M. Isotemporal analysis of the association of objectively measured physical activity with depressive symptoms: results from Hispanic Community Health Study/ Study of Latinos (HCHS/SOL). J Phys Act Health 14: 733739, 2017. doi: 10.1123/jpah.2016-0648.

17) van Roekel EH, Bours MJ, Breedveld-Peters JJ, Willems PJ, Meijer K, Kant I, van den Brandt PA, Beets GL, Sanduleanu S, Weijenberg MP. Modeling how substitution of sedentary behavior with standing or physical activity is associated with health-related quality of life in colorectal cancer survivors. Cancer Causes Control 27: 513-525, 2016. doi: 10.1007/s10552-016-0725-6.

18) Dillon CB, McMahon E, O’Regan G, Perry IJ. Associations between physical behaviour patterns and levels of depressive symptoms, anxiety and well-being in middle-aged adults: a cross-sectional study using iso- temporal substitution models. BMJ Open 8: e018978, 2018. doi: 10.1136/bmjopen-2017-018978.

19) Yasunaga A, Shibata A, Ishii K, Koohsari MJ, Oka K. Cross-sectional associations of sedentary behaviour and physical activity on depression in Japanese older adults: an isotemporal substitution approach. BMJ Open 8: e022282, 2018. doi: 10.1136/bmjopen-2018-022282.

20）小野寺由美子, 塙 智史, 北川瑛梨子, 甲斐裕子, 北濃成樹, 永松俊哉, 朽木 勤, 町田修一：就業時間内の短時間の軽 体操が勤労者の気分に及ぼす効果: リラックスおよびリ フレッシュ体操の比較, 人間ドック, 32: 207, 2017.

21) Ohkawara K, Oshima Y, Hikihara Y, IshikawaTakata K, Tabata I, Tanaka S. Real-time estimation of daily physical activity intensity by a triaxial accelerometer and a gravity-removal classification algorithm. Br J Nutr 105: 1681-1691, 2011. doi: 10.1017/ S0007114510005441.

22) Oshima Y, Kawaguchi K, Tanaka S, Ohkawara K, Hikihara Y, Ishikawa-Takata K, Tabata I. Classifying household and locomotive activities using a triaxial accelerometer. Gait Posture 31: 370-374, 2010. doi: 10.1016/j.gaitpost.2010.01.005.

23) Mâsse LC, Fuemmeler BF, Anderson CB, Matthews CE, Trost SG, Catellier DJ, Treuth M. Accelerometer data reduction: a comparison of four reduction algorithms on select outcome variables. Med Sci Sports Exerc 37: S544-S554, 2005. doi: 10.1249/01. mss.0000185674.09066.8a.

24) Tremblay MS, Aubert S, Barnes JD, Saunders TJ, Carson V, Latimer-Cheung AE, Chastin SFM, Altenburg TM, Chinapaw MJM. Sedentary Behavior Research Network (SBRN) - terminology consensus project process and outcome. Int J Behav Nutr Phys Act 14: 75, 2017. doi: 10.1186/s12966-017-0525-8.

25) Norton K, Norton L, Sadgrove D. Position statement on physical activity and exercise intensity terminology. J Sci Med Sport 13: 496-502, 2010. doi: 10.1016/ j.jsams.2009.09.008.

26) Furukawa TA, Kawakami N, Saitoh M, Ono Y, Nakane Y, Nakamura Y, Tachimori H, Iwata N, Uda H, Nakane H, Watanabe M, Naganuma Y, Hata Y, Kobayashi M, Miyake Y, Takeshima T, Kikkawa T. The performance of the Japanese version of the K6 and $\mathrm{K} 10$ in the world mental health survey Japan. Int J Methods Psychiatr Res 17: 152-158, 2008. doi: 10.1002/ mpr.257.

27) Sakurai K, Nishi A, Kondo K, Yanagida K, Kawakami N. Screening performance of K6/K10 and other screening instruments for mood and anxiety disorders in Japan. Psychiatry Clin Neurosci 65: 434-441, 2011. doi: 10.1111/j.1440-1819.2011.02236.x.

28) Shimazu A, Schaufeli WB, Kosugi S, Suzuki A, Nashiwa H, Kato A, Sakamoto M, Irimajiri H, Amano S, Hirohata K, Goto R, Kitaoka-Higashiguchi K. Work engagement in Japan: validation of the Japanese version of the utrecht work engagement scale. Appl 
Psychol Int Rev 57: 510-523, 2008. doi: 10.1111/j.14640597.2008.00333.x.

29) Schaufeli WB, Salanova M, González-Romá V, Bakker $\mathrm{AB}$. The measurement of engagement and burnout: a two sample confirmatory factor analytic approach. $J$ Happiness Stud 3: 71-92, 2002.

30) Schaufeli WB, Bakker AB, Salanova M. The measurement of work engagement with a short questionnaire: a cross-national study. Educ Psychol Meas 66: 701716, 2006. doi: 10.1177/0013164405282471.

31) Luppino FS, de Wit LM, Bouvy PF, Stijnen T, Cuijpers P, Penninx BW, Zitman FG. Overweight, obesity, and depression: a systematic review and meta-analysis of longitudinal studies. Arch Gen Psychiatry 67: 220-229, 2010. doi: 10.1001/archgenpsychiatry.2010.2.

32) Kleppa E, Sanne B, Tell GS. Working overtime is associated with anxiety and depression: the Hordaland health study. J Occup Environ Med 50: 658-666, 2008. doi: 10.1097/JOM.0b013e3181734330.

33) Rogerson PA. Statistical methods for geography. SAGE Publications Ltd, London, UK, 2001.

34) Halbesleben JRB. A meta-analysis of work engagement: relationships with burnout, demands, resources, and consequences. In: Work engagement: $A$ handbook of essential theory and research Vol. 8 (Bakker AB,
Leiter MP, eds.), Physiology press, NY, USA, 102-117, 2010.

35) Munir F, Houdmont J, Clemes S, Wilson K, Kerr R, Addley K. Work engagement and its association with occupational sitting time: results from the Stormont study. BMC Public Health 15: 30, 2015. doi: 10.1186/ s12889-015-1427-9.

36) van Berkel J, Proper KI, van Dam A, Boot CRL, Bongers PM, van der Beek AJ. An exploratory study of associations of physical activity with mental health and work engagement. BMC Public Health 13: 558, 2013. doi: 10.1186/1471-2458-13-558.

37) Hamer M, Coombs N, Stamatakis E. Associations between objectively assessed and self-reported sedentary time with mental health in adults: an analysis of data from the health survey for England. BMJ Open 4: e004580, 2014. doi: 10.1136/bmjopen-2013-004580.

38) Craft LL, Perna FM. The benefits of exercise for the clinically depressed. Prim Care Companion J Clin Psychiatry 6: 104-111, 2004.

39) Inoue A, Kawakami N, Tsuchiya M, Sakurai K, Hashimoto H. Association of occupation, employment contract, and company size with mental health in a national representative sample of employees in Japan. J Occup Health 52: 227-240, 2010. 